\title{
INVESTIGATION AND OPTICAL EVALUATION OF PRECURSORS FOR THE PHOTODEPOSITION OF NANOSIZED ZnS AMORPHOUS THIN FILMS
}

\author{
MARISOL TEJOS R ${ }^{*}$, BÁRBARA G. ROLÓN ${ }^{2}$, RODRIGO DEL RÍO', GERARDO CABELLO \\ ${ }^{1}$ Facultad de Ciencias, Universidad de Valparaíso. Av. Gran Bretaña 1111 Playa Ancha Valparaíso, Chile. \\ ${ }^{2}$ FIMEE, Universidad de Guanajuato, 36730. Salamanca. México. \\ ${ }^{3}$ Instituto de Química, Universidad Católica de Valparaíso. Av. Brasil 2950 Valparaíso, Chile. \\ ${ }^{4}$ Departamento de Ciencias Básicas. Facultad de Ciencias, Universidad del Bio Bio, Chile.
}

(Received 13 ${ }^{\text {th }}$ March 2007 - Accepted $15^{\text {th }}$ June 2007)

\begin{abstract}
Thin amorphous nanostructured $\mathrm{ZnS}$ films have been photochemically obtained by means of direct UV radiation $(\lambda=254 \mathrm{~nm})$ of the complex $\mathrm{Zn}\left[\left(\mathrm{CH}_{3}\right)_{2} \mathrm{CHCH}_{2} \mathrm{OCS}_{2}\right]_{2}$ deposited on $\mathrm{Si}(100)$ and on ITO glass through the spin-coating technique. The UV photolysis of thin films of Zinc Xanthate complex results in the loss of all ligands from the coordination sphere. The binding energy values for as-deposited films in X-Ray Photoelectron Spectra were $1022.7 \mathrm{eV}$ for $\mathrm{Zn} 2 \mathrm{p} 3$ and $163-169 \mathrm{eV}$ for $\mathrm{S} 2 \mathrm{p}$. The as-deposited film showed a non-uniform rough surface with a root-mean-square ( $\mathrm{rms}$ ) roughness of $48.5 \mathrm{~nm}$ and a maximum height, Rmax, of $460.5 \mathrm{~nm}$. The annealed $\mathrm{ZnS}$ films showed a uniform and a reasonably light but smooth surface with a rms roughness of $43.0 \mathrm{~nm}$ and Rmax of $274.2 \mathrm{~nm}$. The optical band gap was determined and found to be $3.2 \pm 0.01 \mathrm{eV}$ and $3.25 \pm 0.01 \mathrm{eV}$.
\end{abstract}

Keyword: Amorphous Materials; Photochemistry Synthesis; Atomic Force Microscopy; Optical Properties.

\section{INTRODUCTION}

$\mathrm{ZnS}$ nanocrystalline thin films have been used for a wide variety of technological applications. As a general trend, phase composition, as well as thermal stability and morphology, which also strongly influence the functional behaviour of $\mathrm{ZnS}$ devices, is directly dependent on the mechanism of the deposition and processing conditions. The thin films are obtained by different physical methods (e.g., thermal evaporation ${ }^{1}$, sputtering ${ }^{2,3}$ and epitaxial growth ${ }^{4}$ ). Or they are also obtained by chemical methods (e.g., electrochemical deposition (ECD) ${ }^{5,6}$ chemical vapour deposition $(\mathrm{CVD})^{7}$ and chemical bath deposition $(\mathrm{CBD})^{8,9}$. The physical methods are expensive but generally give more reliable and reproducible results. Most of the chemical methods are costeffective, but their full potential for obtaining device quality films has not been fully explored ${ }^{5}$. Recently, the photochemical deposition method (PCD) has been developed to deposit compound semiconductor thin films from an aqueous solution ${ }^{10-15}$. In this method a substrate is held in an aqueous solution containing thiosulfate ions and irradiated with UV light. Then a sulfide thin film is deposited on the irradiated region of the substrate.

Crystalline $\mathrm{ZnS}$ is an important semiconductor material with a wide direct band gap (3.5-3.7 eV) $)^{5,6}$ at room temperature with high transparency, and it is a promising material for future applications such as window layers of solar cells, data storage, data transfer, and coatings which are sensitive to UV light (photoluminescents and photoconductors devices) ${ }^{6,9}$. The photoconductors are normally semiconductors which exhibit a photoconductive effect that is an enhancement in the electrical conductivity of a material by the absorption of suitable photons. ${ }^{16}$

This work reports on the preparation and characterization of $\mathrm{ZnS}$ thin films for their potential use as photoconductor devices, using Zinc xanthate complexes as source materials, for the direct method ${ }^{17-21}$ photochemical deposition

This technique of film preparation is very attractive because it is inexpensive, simple and capable of getting a deposition of optically smooth, and homogenous layers of amorphous $\mathrm{ZnS}$.

\section{EXPERIMENTAL}

\section{1.- General procedure}

The FT-IR (Fourier transformed infrared) spectra were obtained with $4 \mathrm{~cm}^{-1}$ resolution in a Perkin Elmer Model 1605 FT-IR spectrophotometer. UV spectra were obtained in a Hewlett-Packard 8452-A diode array spectrophotometer. Xray photoelectronic (XPS) spectra were obtained in a XPS-Auger Perkin Elmer Model PHI 1257. Atomic Force Microscopy was performed with a Nanoscope IIIa (Digital Instruments, Santa Barbara, CA) in contact mode. Film thickness was determined using a Leica DMLB optical microscope with a Michelson interference attachment.
The solid state photolysis was carried out at room temperature under a UVS-38 $\lambda=254 \mathrm{~nm}$ lamp equipped with two $8 \mathrm{~W}$ tubes, in an air atmosphere. Progress of the reactions was monitored by determining the FT-IR spectra at different time intervals, following the decrease in IR absorption of the complexes.

The substrates for the deposition of films were borosilicate glass slides (Fischer, $2 \times 2 \mathrm{~cm}$ ) and n-type silicon $(100)$ wafers $(1 \times 1 \mathrm{~cm})$ obtained from WaferNet, San Diego, CA. Prior to use, the wafers were cleaned successively with ether, methylene chloride, ethanol, aqueous HF (50:1) for 30 seconds and finally with deionized water. They were dried in an oven at $110^{\circ} \mathrm{C}$ and stored in glass containers.

\section{2.- Synthesis of Xanthates Zn complexs.}

The reagents used in the synthesis of O-isoamyl ditiocarbonate ${ }^{22}$, were from Merck and used without further purification. Into a $250 \mathrm{ml}$ round-bottomed flask, fitted with reflux condenser, and $1.40 \mathrm{gr}(0.025 \mathrm{~mol})$ of potassium hydroxide pellets and $5.56 \mathrm{gr}(6.95 \mathrm{ml})$ of isoamyl alcohol were placed inside and heated under a reflux for 1 hour to allow cooling and decanting of the liquid of the residual solid into another dry flask. $1.50 \mathrm{ml}(0.025 \mathrm{~mol})$ of carbon disulfide was slowly added and constantly shaken. The resulting almost-solid mass was cooled on ice and then filtered and washed with three $25 \mathrm{ml}$ portions of ether. The $o$-isoamyl dithiocarbonate was dried in vacuum desiccators (yield $=65 \%$ ).

Potassium $o$-isoamyl dithiocarbonate $(0.010 \mathrm{~mol})$ in $25 \mathrm{ml}$ of methanol (Merck p.a.) and $\mathrm{Zn}\left(\mathrm{CH}_{3} \mathrm{COO}\right)_{2} 2 \mathrm{H}_{2} \mathrm{O}$ (Merck p.a.) $(0.010 \mathrm{~mol})$ in $25 \mathrm{ml}$ of water, were loaded in a $150 \mathrm{ml}$ flask and the solution mixture was stirred at room temperature until a white solid was obtained. Afterward, the product was extracted in $\mathrm{CH}_{2} \mathrm{Cl}_{2}$ and dried over anhydrous $\mathrm{Na}_{2} \mathrm{SO}_{4}$.

\section{3.- Preparation of amorphous thin films.}

The thin films of the precursor complexes were prepared by the following procedure: A silicon chip was placed on a spin coater and rotated at a speed of 1500 RPM. A portion $(0.1 \mathrm{ml})$ of a solution of the xanthate complex in THF was dispensed onto the silicon chip and allowed to spread. The motor was then stopped and a thin film of the complex remained on the chip. The quality of the films was examined by an optical microscope to $1000 \mathrm{X}$.

\section{4.- Photolysis of complexes as films on $\mathrm{Si}(100)$ surfaces.}

All photolysis experiments were done following the same procedure. A film of the xanthate complex was deposited on n-type $\mathrm{Si}$ (100) by spin-coating from a THF solution. This resulted in the formation of a smooth, uniform coating on the chip. The FT-IR spectrum of the starting film was first obtained. The chip was then placed under a UV $254 \mathrm{~nm}$ lamp. After the FT-IR spectrum showed no evidence of the starting material, the chip was rinsed several times 
with dry THF to remove any organic products remaining on the surface, prior to analysis.

\section{RESULTS AND DISCUSSION}

\section{1.- Photochemistry of thin films of Xanthates $\mathrm{Zn}$ (II) complexs.}

The FT-IR spectrum of thin films of the zinc (II) O-isobutylxanthate complex of general formula $\mathrm{Zn}\left[\left(\mathrm{CH}_{3}\right)_{2} \mathrm{CHCH}_{2} \mathrm{OCS}_{2}\right]_{2}$ is shown in Fig 1. This exhibited one band at 1064 , and two bands at 1201 and $1235 \mathrm{~cm}^{-1}$. The first absorption band observed has been assigned to the $\mathrm{C}=\mathrm{S}$ group stretching modes of the zinc xanthate complex, and the other two bands can be assigned C-O-C group symmetric and asymmetric stretching respectively.

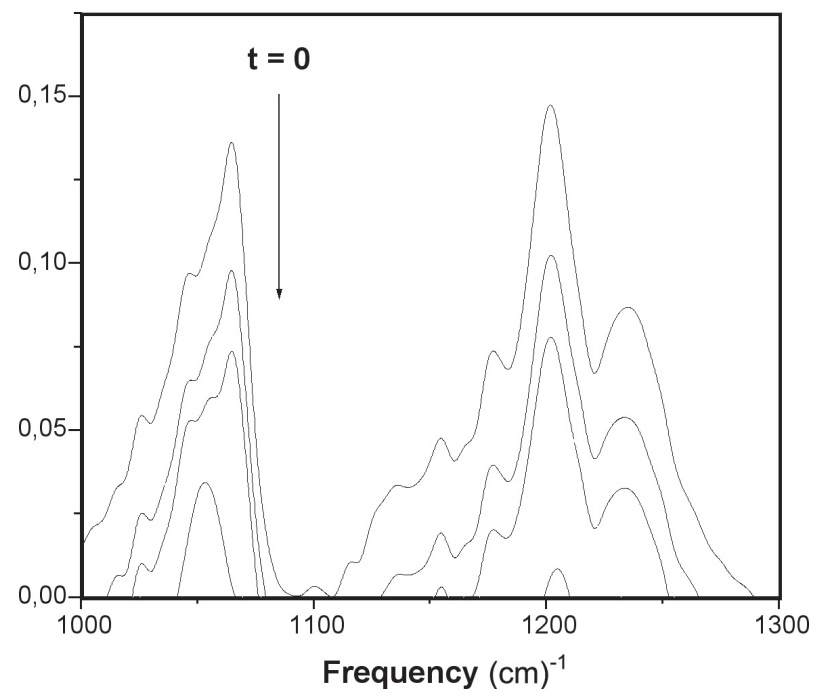

Fig.1 FT-IR spectral changes associated with the photolysis for 24 hours of film of Bis (O-isobutylxanthate) Zn(II) deposited on $\mathrm{Si}$ (100).

These bands associated with the complex decrease in intensity as a result of the photolysis and no new bands become apparent in the spectrum. The decrease in intensity of each absorption band appear to be consistent with the original intensity and doesn't give an indication of a thermally stable intermediate. Exhaustive photolysis results in the loss of all bands associated with the starting complex. At the end of the photolysis ( $24 \mathrm{~h}$ irradiation) there are no detectable absorptions in the infrared spectrum.

\section{2.- Film Composition.}

Fig. 2 shows the XPS spectrum in the range of $0-1100 \mathrm{eV}$ of as-deposited $\mathrm{ZnS}$ thin films, prepared under optimal conditions in the photolysis. The figure 2 shows the XPS peaks of $\mathrm{Zn}, \mathrm{S}$ and some impurities such as carbon and oxygenated species. The position of the signal of $\mathrm{C}$ at $287 \mathrm{eV}$ suggests that it is bonded to $\mathrm{O}$, presumably of the organic compounds since the sample was free of carbonates. ${ }^{23}$

The binding energy values are $1022.7 \mathrm{eV}$ for $\mathrm{Zn} 2 \mathrm{p} 3$ and $163-169 \mathrm{eV}$ for $\mathrm{S}$ $2 \mathrm{p}$. These results are consistent with values reported by other authors ${ }^{24,25}$. The $\mathrm{O} 1 \mathrm{~s}$ peak located at $532 \mathrm{eV}$ is probably due to the oxygen chemisorbed on the surface in the form of $\mathrm{ZnO}$ during the photolysis process. The semiquantitative analysis results show that the $\mathrm{O}$ content of as-deposited decreases after sputtering to remove the surface layer (see Fig. 2). However, the films are still $\mathrm{S}$ deficient and $\mathrm{O}$ rich, because of the presence of one small S $2 \mathrm{p}$ band at 169.5 $\mathrm{eV}$, which indicates that the oxidation may take place during deposition ${ }^{26,27}$ and corresponds to species $\left(\mathrm{SO}_{\mathrm{x}}\right)$ associated to products of oxidation mainly in the surface of the as-deposited films ${ }^{28,29}$.

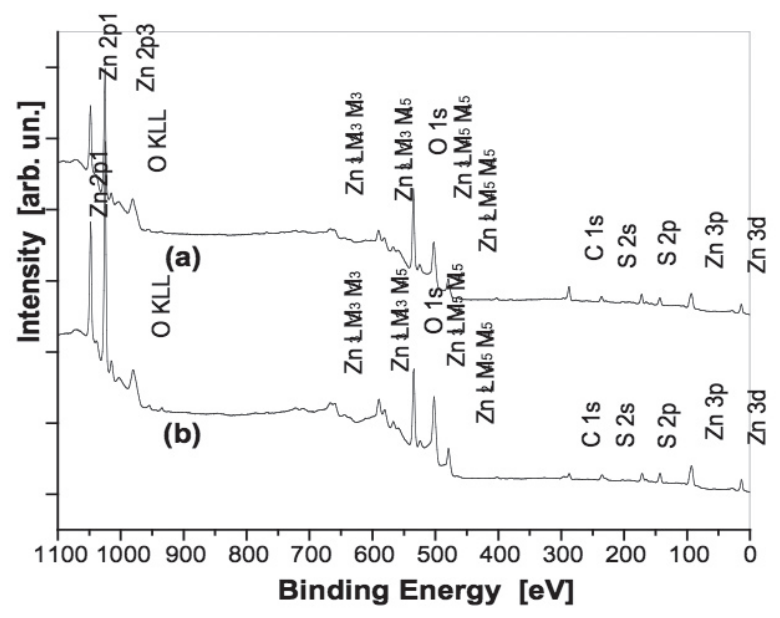

Fig.2 XPS wide scan of as-deposited $\mathrm{ZnS}$ thin films (a) surface (b) $2 \mathrm{~min}$ $\mathrm{Ar}^{+}$sputtering.

Ferrizz et al. $^{30}$ found that the peak associated with $160-170 \mathrm{eV}$ at room temperature is related to molecularly adsorbed $\mathrm{SO}_{2}$, while the higher temperature peaks are due to decomposition of adsorbed sulfates. XPS results show that at room temperature a small fraction of the adsorbed $\mathrm{SO}_{2}$ is oxidized to $\mathrm{SO}_{4}^{-2}$ using oxygen supplied by metal oxide.

Photochemistry has been used in this work in a solid state to obtain $\mathrm{ZnS}$ from a thin film of zinc xanthate. The complex precursor, zinc xanthate, possesses oxygen close to the coordination sphere which leads us to believe that this reaction generates oxygenated species like zinc oxide as a secondary product. As the signal at $532 \mathrm{eV}$ did not reduce, it was determined that the oxygenated species were only superficial in nature.

In results not yet published, we found that the ligand in the photochemical deposition in the obtaining of metallic sulfide is a factor of great relevance. We used a complex of xanthate and dithiocarboxylate with the same metallic ion. The Auger revealed almost total diminution of oxygen when the ligand was dithiocarboxylate, and demonstrated that in this case the oxygen was superficial, while the xanthate, even after sputtering, continued to show a large quantity of oxygen.

Fig. 3 shows typical morphologies of the $\mathrm{ZnS}$ samples revealed by AFM. The images presented in (a) and (b) correspond to as-deposited films and to films annealed at $500{ }^{\circ} \mathrm{C}$ respectively. The as-deposited film showed a nonuniform rough surface with a root-mean-square (rms) roughness of $48.5 \mathrm{~nm}$ and a maximum height, Rmax, of $460.5 \mathrm{~nm}$. This surface can be described as a conglomerate random roughness, which is characteristic of an amorphous deposit. (a)

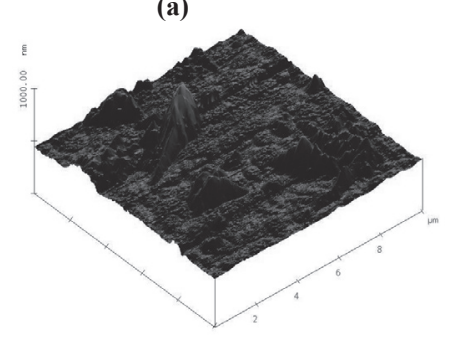

(b)

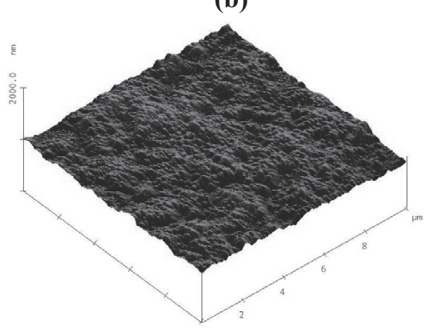

Fig.3 Three-dimensional AFM images of the ZnS films deposited on Si (100). Images size $10 \times 10 \mu \mathrm{m}$ (a) as-deposited and (b) the $\mathrm{ZnS}$ films annealed at $500{ }^{\circ} \mathrm{C}$.

On the other hand, the annealed ZnS films showed a uniform and a reasonably light but smooth surface with a rms roughness of $43.0 \mathrm{~nm}$ and Rmax of $274.2 \mathrm{~nm}$. All these deposits annealed did not present crystallinity; in fact an analysis performed by XRD did not show clear signs of any crystalline structure. 


\section{Optical properties.}

Optical transmission for the as-deposited films on ITO glass substrates were measured in the range $300-800 \mathrm{~nm}$ using a spectrophotometer. The spectral transmittance curves of these films are shown in Fig. 4.

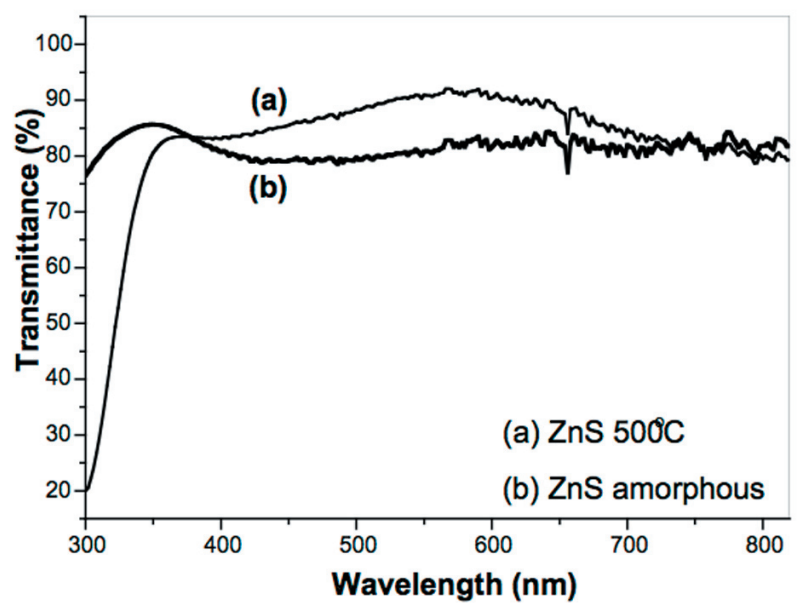

Fig. 4 Transmission spectra of (a) as-deposited $\mathrm{ZnS}$ films and (b) $\mathrm{ZnS}$ films annealed at $500{ }^{\circ} \mathrm{C}$.

The films present a good transmission. The as-deposited films present an absorption edge near $300 \mathrm{~nm}$ and a maximum of transmission (80\%). The films annealed at $500{ }^{\circ} \mathrm{C}$ for 4 hours presented increased transmission in the visible range above $85-90 \%$. This result can be attributed to decreases in thickness; the films were annealed as to change the morphology surface and the stoichiometry of these films.

The morphologies of two $\mathrm{ZnS}$ (as-deposited and annealed) thin films are partially different, which also affects the transmission of visible light. Obviously, the rough surface morphology will reduce the transmission in visible region. On the other hand, it has been reported that the raising of temperature applied to the films increases transmittance which attributes to the improvement of crystallinity and stoichiometry ${ }^{27}$.

The fundamental absorption edge of semiconductors corresponds to the threshold for charge transitions between the highest nearly filled band and the lowest nearly empty band. The absorption is very small for photon energy, much less than the energy gap, and it increases significantly for higher photon energies.

The inter-band absorption theory shows that absorption coefficient near the threshold incident energy, is given by the following relation Eq 2. ${ }^{31}$.

$$
(\alpha h v)=\mathrm{A}\left(h v-\mathrm{E}_{\mathrm{g}}\right)^{\mathrm{n}} \quad \text { Eq. } 2
$$

Where $\mathrm{A}$ is the probability parameter for the transition and $\mathrm{E}_{\mathrm{g}}$ the optical gap energy of the material and $n$ the exponent. The exponent $n$ determines the type of electronic transitions causing the absorption. To allow direct transitions, the coefficient $n$ is equal to $1 / 2$ and for indirectly allowed transitions $n=2 .{ }^{31,32}$

The value of the optical energy gap for different films has been calculated by extrapolating the straight line portions of the $(\alpha h v)^{\mathrm{n}}$ versus $h v$ curves. Fig. 5 shows the plot of $(\alpha h v)^{1 / 2}$ versus the incident radiation energy $h v(\mathrm{eV})$. The values of the direct band gap, $\mathrm{E}_{\mathrm{g}}$, for as-deposited $\mathrm{ZnS}$ amorphous and annealed at $500{ }^{\circ} \mathrm{C}$ films were $3.2 \pm 0.01 \mathrm{eV}$ and $3.25 \pm 0.01 \mathrm{eV}$ respectively. The established values for the direct band gap of $\mathrm{ZnS}$ fluctuate between 3.54 and $3.67 \mathrm{eV}^{7}$. The values obtained can be attributed to the defects of the deposits like the partial oxidation of these films, as shown in the XPS analysis. However it has been reported that due to the presence of oxygen in the $\mathrm{ZnS}$ films, the oxygen combined with zinc to form $\mathrm{ZnO}$, which has a lower energy gap ${ }^{26-33}$.

It has been reported that the existence of impurities in thin films of $\mathrm{ZnS}$ can cause a low light value in the band gap optic, which can be associated with the grain size in the films depending on the preparative conditions of the film ${ }^{34}$. In this case the presence of species $\mathrm{SO}_{\mathrm{x}}$ as an impurity have conducted light low in the band gap.
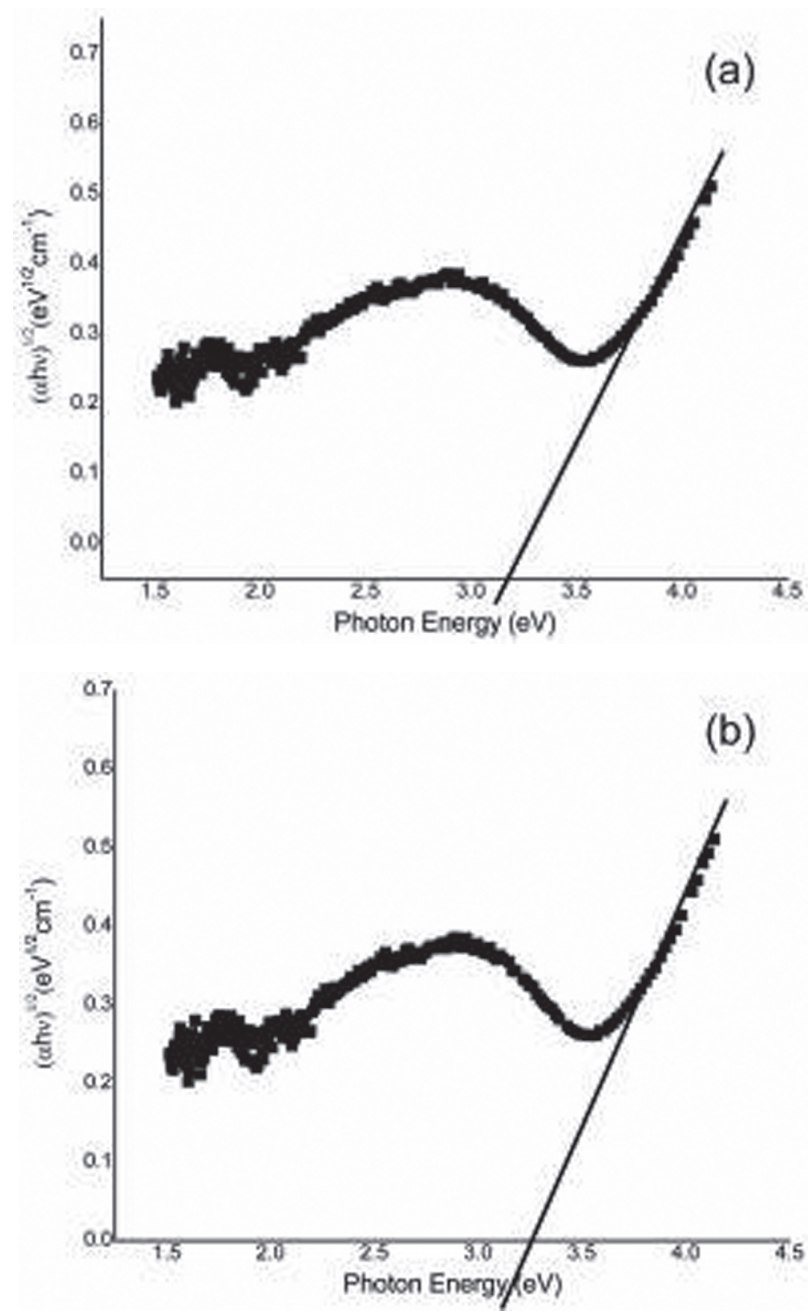

Fig.6 Dependence of $(\alpha h v)^{1 / 2}$ as function of the photon energy $h v$, for (a) as-deposit amorphous $\mathrm{ZnS}$ thin films (b) $\mathrm{ZnS}$ thin films annealed at $500{ }^{\circ} \mathrm{C}$.

\section{CONCLUSIONS}

The results show that the methodology applied in this research is quick, and a direct alternative for the deposition of the metal sulfide thin films. Nevertheless, there are still other parameters that should be looked at to optimize the process, such as the type of precursor complex, inert atmosphere in the deposition of the films and a finished study of the temperature effect.

\section{ACKNOWLEDGEMENTS}

The authors would like to thank Universidad de Valparaíso (Proyect DIPUV 08-2003) for financial support.

\section{REFERENCES}

1. Yan Li, C. Ye, X. Fang, L. Yang, Y. Xiao, L. Zhang. Nanotechnology, 16, 501, (2005).

2. S.K. Mandal, S. Chaudhuri, A.K. Pa., Thin Solid Films, 350, 209, (1999).

3. L-X. Shao, K-H. Chang, H-L. Hwang. Appl. Surf. Sci. 212, 305 (2003).

4. L. Manna, E. C. Scher, L. S. Li, A. P. Alivisatos. J. Am. Chem. Soc. 124(24), 7136, (2002).

5. N. Fathy, R. Kobayashi, M. Ichimura. Mat. Sci. Eng. B 107, 271 (2004).

6. N. Fathy, M. Ichimura, Sol. Energ. Mat. Sol. C. 87, 747 (2005). 
7. D. Barreca, A. Gasparotto, C. Maragno, E. Tondello, J. Electrochem. Soc. 151, G428 (2004).

8. S. D. Sartale, B. R. Sankapal, M. Lux-Steiner, A. Ennaoui. Thin Solid Films. 480-481, 168 (2005).

9. R. Zhai, S. Wang, H. Xu, H. Wang, H. Yan. Mater. Lett. 59, 1497 (2005).

10. M. Gunasekaran, R. Gopalakrishnan, P. Ramasamy. Mater. Lett. 58, 67 (2003).

11. R. Kumaresan, M. Ichimura, E. Arai. Thin Solid Films. 414, 25 (2002).

12. J. Podder, R. Kobayashi, M. Ichimura. Thin Solid Films. 472, 71 (2005).

13. S. Soundeswaran, O. Senthil Kumar, P. Ramasamy, D. Kabi Raj, D.K. Avasthi, R. Dhanasekaran, Physica B. 355, 222 (2005).

14. M. Ichimura, T. Narita, K. Masui. Mat. Sci. Eng. B. 96, 296 (2002).

15. R. Kumaresan, M. Ichimura, N. Sato, P. Ramasamy. Mat. Sci. Eng. B. 96, 37, (2002).

16. D. P. Amalnerkar, Mater. Chem. Phys. 60, 1, (1999).

17. M. Tejos, R. Schrebler, F. R. Díaz, M. A. del Valle, Thin Solid Films. 409, $172,(2002)$

18. G. E. Buono-Core, M. Tejos, G. Cabello, N. Guzmán, R. H. Hill, Mater. Chem. Phys. 96, 98 (2006).

19. M. Tejos, G.E. Buono-Core, F.R. Díaz, M.A. del Valle, J. Palomares J. Chil. Chem. Soc. 49(4), 297 (2004).

20. G.E. Buono-Core, M. Tejos R., R. Schrebler and R.H. Hill. J. Chil. Chem. Soc. 49(3), 223 (2004)

21. G. Buono-Core, G. Cabello, Espinoza, H. Klahn, M. Tejos and R. Hill. J. Chil. Chem. Soc. 51(3), 950 (2006).
22. VOGEL'S Textbook of Practical Organic Chemistry Fifth Edition Addison Wesley Longman Singapore Pte Ltd. Singapore, 1998, p. 792.

23. J. F. Moulder, W.F. Stickle, P.E. Sobol, and K.D. Bomben. Handbook of X-ray Photoelectron Spectroscopy. Perkin-Elmer Corp., Eden Prairie, MN. 1992.

24. X. Jiang, Y. Xie, J. Lu, L. Zhu, W. He, Y. Qian. Chem. Mater. 13, 1213 (2001).

25. J. F. Xu, W. Ji, J. Y. Lin, S.H. Tang, Y. W. Du, Appl. Phys. A. 66, 639 (1998).

26. B. Su, K. L. Choy. J. Mater. Chem. 10, 949 (2000).

27. B. Elidrissi, M. Addou, M. Regragui, A. Bougrine, A. Kachouane, J. C. Bernede. Mater. Chem. Phys. 68, 175 (2001).

28. D. S. Boyle, P. O-Brien, D.J. Otway, O. Robbe. J. Mat. Chem. 9, 725 (1999).

29. D.S. Boyle, S. Hearne, D.R. Johnson, P. O-Brien. J. Mat. Chem. 9, 2879 (1999).

30. R. M. Ferrizz, R. J. Gorte and J. M. Vohs. Catal. Lett. 82(1-2), 123 (2002)

31. A. Bouzidi, N. Benramdane, H. Tabet-Derraz, C. Mathieu, B. Khelifa, R. Desfeux. Mater. Sci. Eng. B. 97, 5 (2003).

32. K. V. Madhuri, B. S. Naidu, O. M. Hussain. Mat. Chem. Phys. 77, 22 (2002).

33. J. Pantoja Enríquez, X. Mathew. Sol. Energ. Mat. Sol. C. 76, 313 (2003).

34. B. Bhattacharjee, D. Ganguli, K. Iakoubovskii, A. Stesmans, S. Chaudhuri. Bull. Mater. Sci. 25, 175 (2002). 